Title: Improving the outcome of acute cholecystitis: the non-standardized treatment must no longer be employed

Authors: Juan Ignacio González-Muñoz ${ }^{1}$, María Angoso ${ }^{1}$, José María Sayagués ${ }^{2}$, Ana Belén Sánchez-Casado ${ }^{1}$, Alvaro Hernández ${ }^{1}$, Antonio Velasco ${ }^{3}$, Luís Muñoz-Bellvis ${ }^{1}$.

${ }^{1}$ Department of General and Digestive Surgery, University Hospital of SalamancaIBSAL, Salamanca, Spain.

${ }^{2}$ Servicio General de Citometría, Departamento de Medicina and Centro de Investigación del Cáncer (IBMCC-CSIC/USAL), Universidad de Salamanca, Salamanca, Spain.

${ }^{3}$ Department of Digestive, University Hospital of Salamanca, Salamanca, Spain.

\title{
Reprint requests to:
}

Corresponding author: Juan Ignacio González-Muñoz, MD, PhD. Department of General and Digestive Surgery, University Hospital of Salamanca-IBSAL, Salamanca, Spain. Paseo de San Vicente 58-182. 37007. Salamanca. Spain. Tfno: (+34) 923291200, ext. 392. e-mail: cardiakez@yahoo.es

Short tittle: Improving the outcome of acute cholecystitis.

Key words: acute cholecystitis, treatment, early surgery.

Disclosure: The authors declare no conflict of interest.

Number of text pages: 17

Tables: 1

Figures: 2

Word count: 2222 


\begin{abstract}
Purpose Therapeutic recommendations of acute cholecystitis are not consistently implemented, which generates greater patient morbidity and higher health care costs. The aim of this article is to evaluate the burden of acute cholecystitis, to detect potentially modifiable variables and to propose a therapeutic strategy that will allow us to improve the quality of care.
\end{abstract}

Methods We carried out a retrospective study of patients who were admitted to the hospital from January 2010 to December 2012 using a univariate analysis of parameters including the admitting department, age, treatment administered and length of stay.

Results A total of 967 patients were admitted to the hospital with a diagnosis of acute cholecystitis, 692 (72\%) to the Surgery department, 257 (26\%) to Internal MedicineDigestive and 18 (2\%) to other departments. 498 (51.5\%) were operated on: 107 (21\%) on an urgent basis, 111 (22\%) at an early stage (<96 hours at diagnosis), 152 (30\%) at a late stage (>96 hours at diagnosis) and 128 (26\%) at a delayed date (other admission). Patients who were admitted into the surgery department were five times more likely to be operated on than patients admitted into other departments $(\mathrm{p}<0.01)$. Patients operated on at a late stage had a longer length of stay than early stage surgery patients $(\mathrm{p}<0.05)$ and than non operated ones $(\mathrm{p}<0.05)$. Patients $<74$ years old were more frequently operated than older ones $(\mathrm{p}<0.05)$.

Conclusions The non-standardized treatment of acute cholecystitis causes high clinical and surgical variability, long average stay, more re-admissions and high hospital costs. Therefore, patients with a diagnosis of acute cholecystitis should be admitted to the Surgery department, thereby increasing the probability of receiving definite treatment. 


\section{Introduction}

Acute cholecystitis is a prevalent disease with a high socioeconomic impact. Approximately $10-15 \%$ of the population presents with cholelithiasis [1, 2]. Although the majority of cases are asymptomatic, complications such as biliary colic (1-4\% yearly) or cholecystitis (20\%) [3, 4] can develop. A third of the patients with acute cholecystitis can develop serious complications such as empyema, obstruction or cholangitis, which are especially common in elderly, diabetic or pregnant patients [5-7].

Many authors show that early stage cholecystectomy in patients with acute cholecystitis is better than conservative treatment and results in lower patient morbidity and hospital costs, even with open surgery [8-14]. In spite of the scientific evidence, it is not a common practice. In the United States, only $30-40 \%$ of cholecystectomies are carried out at an early stage [15, 17]; 20-36\% in the United Kingdom [17-19], 42\% in Japan [20], 51\% in Canada [21], 55\% in Australia [22] and 26\% in Spain [23]. However, after interviewing surgeons, all expressed a desire to carry out cholecystectomies at an early stage but do not do so due to organizational problems [24]. The idea that delayed cholecystitis is technically simpler due to reduced inflammation is not correct. In fact, the risk of wounding the main biliary tract is lower in early stage surgery [25], and the probability of conversion of this condition into a standardized early stage surgery is $8-16 \%$, which is not significantly different from delayed surgery. Twenty five per cent of patients waiting for a delayed cholecystectomy are re-admitted and $18 \%$ require urgent surgical intervention [14, 25-27].

This issue heavily impacts national health systems worldwide, totaling 6.3 billion dollars in the USA [28] and 8.5 million pounds/year in UK [29, 30]. Early stage cholecystectomy leads to a higher quality of life for patients and a savings of $\$ 1000$ 1400 per patient compared to delayed cholecystectomy [12, 29-31]. 
The characteristics of our hospital are comparable to the characteristics of other tertiary level assistance centers with regard to the population served, the technological methods and the patient care. We analyzed the therapeutic strategy utilized in the last three years for patients diagnosed with acute cholecystitis to describe the current clinical guidelines and improve the quality of our patient care. 


\section{Patients and methods}

We conducted a retrospective study of patients admitted to our hospital from 2010 to 2012 with a diagnosis of acute cholecystitis (n=967). For this purpose, we employed the 9th revision of the International Classification of Diseases clinical modification (ICD $9^{\text {th }}$, MC), 8th Spanish edition, utilized by the hospital's Clinical Records department to code all hospital admittances [32]. We utilized the codes 574.0 and 574.1 (acute lithiasic cholecystitis), 574.3 (biliary duct obstruction with acute cholecystitis), 574.6 (acute lithiasic cholecystitis and choledocholithiasis) and 575.0 (acute cholecystitis). We also utilized the HP-HIS corporate clinical software employed in the hospital to obtain the patients' clinical data.

Patients were admitted to the hospital via Emergency Services into the respective departments under the admitting doctor. The urgent and early stage surgeries were performed by 16 surgeons, and the delayed surgeries were performed by all department surgeons. We collected variables including age, admitting department, treatment administered, date when surgery was performed, length of stay and readmissions.

Statistical analyses To describe the study sample, we performed statistical testing using a univariate analysis. Parametric and non-parametric tests were performed according to the distribution of the variable of interest. For all continuous variables, mean values and their standard deviation (SD) and range were calculated using the SPSS software package (SPSS 19.0 Inc, Chicago, IL USA); The frequencies and percentages were calculated for categorical variables, utilizing Pearson's Chi-Squared test (or Fisher's exact test when appropriate) for categorical data analysis. In order to evaluate the statistical significance of differences observed between groups, the Student's $\mathrm{T}$ and the Mann-Whitney $\mathrm{U}$ tests were used for continuous variables, 
depending on whether they displayed or not a normal distribution, respectively. For qualitative variables, the $\mathrm{X}^{2}$ test was applied ( SPSS 19.0 Inc, Chicago, IL USA). The hypothesis comparison was bilateral, with a 0.05 significance level. 


\section{Results}

A total of 967 admissions with a diagnosis of acute cholecystitis were performed, 813 as first admission and 154 were re-admissions of the same diagnosis (16\%). Patients were admitted from the Emergency Room into Surgery ( $n=692 ; 72 \%)$, Internal Medicine-Digestive $(n=257 ; 26 \%)$ and to other departments, Hematology, Nephrology and Medical Oncology Services, $(n=18 ; 2 \%)$. Given the unique characteristics and small numbers of patients admitted to "other departments", they were excluded from this analysis. The median age of the admitted patients was 78 years (range 17-103 years). The mean of stay for patients admitted due to this diagnosis was 10.6 days (range: 1-104 days). Patients with sepsis secondary to acute cholecystitis ( $n=107,11 \%)$ were urgently treated while patients with acute cholecystitis without sepsis ( $\mathrm{n}=860,89 \%)$ were treated by early surgery ( $\leq 96$ hours at diagnosis-admission) $(n=111,11 \%)$ or conservative treatment $(n=597,62 \%)$ or late surgery ( $>96$ hours after diagnosis-admission due to a poor clinical outcome with a median of 10.5 days (range: 5-26 days) ( $\mathrm{n}=152,16 \%)$ without any definite criterion. Of those patients not operated on during the first admission ( $\mathrm{n}=597), 128$ (21\%) were operated in elective form during other admission, 154 (26\%) were readmitted and 72 (12\%) had a subsequent emergency surgical intervention due to complications from acute cholecystitis (Figure 1).

When we analyze the post-ER admitting department and compare this category with the treatment carried out, we observe that patients admitted to Surgery have a five times higher probability of being operated on than Internal Medicine-Digestive patients (298 vs. 36, $\mathrm{p}<0.01$ ). In addition, the patients admitted to Internal Medicine-Digestive have a longer preoperative stay (median 14 vs. 2 days; $\mathrm{p}<0.01$ ), have a longer total stay (median 10 vs. 8 days; $\mathrm{p}<0.05$ ) and are older (81 vs. 76 years; $\mathrm{p}<0.05$ ) than the patients admitted to Surgery. 
After comparing the medians of hospital stay and treatment administered, we find that patients undergoing early stage surgery had a shorter hospital stay than patients undergoing late surgery (median 8 vs. 10 days; $\mathrm{p}<0.05$ ), while patients who did not undergo an operation had a shorter stay than patients who underwent a late surgery (median 8 vs. 10 days; $\mathrm{p}<0.05$ ). Patients who underwent an early stage surgery had a stay length similar to those patients who were not operated on (median 8 days). If we compare age with the treatment administered, we find that the patients who were operated on are younger than the patients who were not operated on (median 74 vs. 80 years; $\mathrm{p}<0.05$ ) (Figure 2). In addition, the patients who underwent early stage surgery were younger than the patients who were not operated on (median 75 vs. 80 years; $\mathrm{p}<0.05$ ), but no significant difference existed with regard to age between patients undergoing an early stage operation and patients undergoing a late stage operation (median 74 vs. 75 years; $\mathrm{p}>0.05$ ).

Morbidity and mortality rates of early and late surgery are shown in Table 1. Although not significantly different, late surgery was more frequently complicated by bile leak than early surgery (11 vs. 7\%, respectively). The median age of patients suffering from any type of complication was the same as of the global series (78 years in both). In contrast, mortality rate was higher in elderly patients (median age 85 years; ranging from 75 to 99 years), especially in those undergoing late surgery (vs. early surgery; $\mathrm{p}=.04)$.

Out of the 198 patients (21\%) for whom conservative treatment failed, 152 (77\%) were operated later on and in the remaining 46 (23\%) percutaneous gallbladder drainage was employed. 


\section{Discussion}

The treatment of acute cholecystitis may cause sepsis and lead to emergency surgery. However, in cases that do not lead to sepsis in the patient, current clinical guideline recommendations have not been developed in the majority of hospitals.

In our institution patients admitted to the Surgery department receive the standard treatment at present $[10,11]$ with a higher probability than patients who are admitted to another department. The literature we reviewed does not collect information regarding the admitting department of patients (medical or surgical), but we confirm its significance. Patients with a diagnosis of acute cholecystitis should be admitted the Surgery department, thereby increasing the probability of receiving definitive treatment.

We medically treat $49 \%$ of cases due to comorbidity, development time of the condition, organizational problems or instruction from the doctor responsible for the patient. Considering all of the randomized prospective studies published to date regarding this treatment and the current clinical guideline recommendations, the treatment of acute cholecystitis should invariably be surgical, except for very high-risk cases or patient refusal. Delayed surgery is not recommended because further increasing the morbidity, total stay and cost of treatment.

Age affects the treatment received. In our series we operate few patients over 74 years old (figure 2). Life expectancy in developed countries is high and is on the rise. In our setting, life expectancy in women is 86.7 years and in men is 80.5 years, with an increase of 3 years in the last decade [33]. This increase that we are more often dealing with elderly patients who have a combination of diseases including acute cholecystitis, for which we should carefully analyze the surgical risk and select the better treatment at the time of operation with/without percutaneous cholecystectomy, individualizing treatment in each case. We do not calculate anesthetic-surgical risk prior to choosing a 
therapeutic strategy. However, we do systematically utilize the ASA classification prior to a planned delayed surgery. In the Tokyo clinical guidelines, organic dysfunction scales are employed (Marshall, SOFA) to evaluate grade III acute cholecystitis [34]. In the therapeutic algorithms of these same guidelines, biliary drainage is recommended for patients with grade II and III acute cholecystitis and high surgical risk [35-36]. Some authors recommend grading acute cholecystitis and employing the ASA, POSSUM, PPOSSUM, APACHE II classification system or other anesthetic risk scales in patients with moderate-severe acute cholecystitis who are at high risk (ASA $>3$, APACHE $>12$ ), as their morbidity is higher, and their mortality surpasses 15\% [37-39]. In critically ill patients, although percutaneous gallbladder drainage is recommended due to its clinical efficacy and simplicity, the morbidity associated with this procedure is high. At present, controversy regarding this treatment exists, and no evidence indicates its use [40-42]. Multicenter randomized studies are currently being conducted that will contribute clarity in this aspect [43]. Due to these restrictions and to differences found regarding anesthetic criteria, we believe that anesthetic-surgical risk should be evaluated in all patients using a risk scale that is independent of the degree of acute cholecystitis. In this way, we would avoid administering conservative treatment to patients instead of surgical procedures. In our hands, conservative treatment fails in approximately $21 \%$ of patients. Therefore, we recommend that patients with the suspected diagnosis of acute cholecystitis would be assessed by an experienced surgeon before rendering the definite treatment employing a risk score scale. Patients with an estimated mortality $<15 \%$ could be considered candidates to surgical treatment.

After evaluating the surgery performed on our patients, we observed that $11 \%$ were operated on urgently. This treatment is recommended for patients with Tokyo grade III cholecystitis, who comprise $1-6 \%$ of all patients [32]. It is possible that in our 
center we are performing urgent surgeries in some patients who do not actually require it, resulting in an overload of urgent care activity and consequently long wait times. A third of the patients undergoing an operation, $16 \%$ of all patients admitted with this diagnosis, were operated on at a late stage. The technical difficulty of cholecystectomies increases with the increasing number of days that have passed since the start of symptoms [26], which also increases length of stay and cost. In addition, delayed surgery causes higher mortality and bile leak in our series. For these reasons, late surgery should be reserved only for high surgical risk patients having a poor clinical response to medical treatment and should always performed by surgeons with experience with this type of intervention [44-45]. More carefully selecting the type of treatment given immediately after the time of admission should reduce this number.

Employing a retrospective study of patient care, we verified that disparities exist between patients who are admitted with a diagnosis of acute cholecystitis. We also found that we do not adequately evaluate the severity of this condition and often do not perform the appropriate surgery according to clinical guidelines at the time of decisionmaking. In consequence, we are not able to offer our patients the best possible treatment with our currently available resources, the hospital stay is longer, and the price of hospital care is higher.

We propose that patients with a diagnosis of acute cholecystitis be admitted to Surgery department and that they be selected based on acute cholecystitis severity criteria, that risk be calculated using a risk scale (P-POSSUM, ACS NSQIP), that we apply the therapeutic algorithms recommended by current clinical guidelines and that patients be treated by surgeons who have experience with this type of intervention to reduce morbidity, re-admission, average stay and hospital costs. 
With the limitations of a retrospective study, we can conclude from our observations that the non-standardized treatment of cholecystitis causes high clinical and surgical variability, long average stay, more re-admissions and high hospital costs. Late surgery has higher mortality and bile leak than early one. Therefore, we propose the development of a standardized strategy for the treatment of acute cholecystitis.

Acknowledgments: The authors are grateful to Dra. M. Teresa Santos and Ms. Rosa María Hernández for their contributions to collecting the data and D. Ciprián for help in statistical analysis. 


\section{References}

1. Elwood DR (2008) Cholecystitis. Surg Clin North Am 88:1241-52.

2. Bates $T$, Harrison $M$, Lowe $D$ et al (1992) Longitudinal study of gallstone prevalence at necropsy. Gut 33:103-107.

3. McSherry CK, Ferstenberg H, Calhown WF et al (1985) Natural history of diagnosed gallstone disease in symptomatic and asymptomatic patients. Ann Surg 202:59-63.

4. Carter HR, Cox RL, Polk HCJr (1987) Operative therapy for cholecystitis and cholelithiasis: trends over tree decades. Am Surg 53:565-8.

5. Hickman MS, Schwesinger WH, Page CP (1988) Acute cholecystitis in the diabetic: a case-control study of outcome. Arch Surg, 123:409-11.

6. Halldestam I, Enell EL, Kullman E et al (2004) Development of symptoms and complications in individuals with asymptomatic gallstones. Br J Surg 91:734-8.

7. Lee HK, Han HS, Min SK (2005) Sex-based analysis of the outcome of laparoscopic cholecystectomy for acute cholecystitis. Br J Surg 92:463-6.

8. Jarvinen HJ, Hastbacka J (1980) Early cholecystectomy for acute cholecystitis: a prospective randomized study. Ann Surg 191:501-5.

9. Norrby S., Herlin P., Holmin T et al (1983) Early or delayed cholecystectomy in acute cholecystitis? A clinical trial. Br J Surg 70:163-5.

10. Overby DW, Apelgren KN, Richardson W et al (2010) SAGES guidelines for the clinical application of laparoscopic biliary tract surgery. Surg Endosc 24:2368-86.

11. Takada T, Strasberg S, Solomkin JS et al (2013) Updated Tokyo guidelines for the management of acute cholangitis and cholecystitis. J Hepatobiliary Pancreat Sci 20:1-7.

12. Gutt CN, Encke J, Koninger J et al (2013) Acute cholecystitis. Early versus delayed cholecystectomy. A multicenter randomized trial. (ACDC study, NCT 00447304). Ann Surg 258(3):385-93.

13. Strasberg SM (2008) Acute calculous cholecystitis. N Engl J Med 358(26):2804-11.

14. Gurusumany KS, Samraj K (2006) Early versus delayed laparoscopic cholecystectomy for acute cholecystitis. Cochrane Database Syst Rev CD005440.

15. Livingstone EH, Rege RV (2004) A nationwide study of conversion from laparoscopic to open cholecystectomy. Am J Surg 188:205-11.

16. Casillas R, Yegiyants S, Collins C (2008) Early laparoscopic cholecystectomy is the preferred management of acute cholecystitis. Arch Surg 143(6):533-37. 
17. Cameron IC, Chandwick C, Phillips J et al (2004) Management of acute cholecystitis in UK hospitals: time for a change. Postgrad Med J 80:292-4.

18. Senapati PS, Bhattarcharya D, Harinath G et al (2003) A survey of timing and approach to the surgical management of cholelithiasis in patients with acute biliary pancreatitis and acute cholecystitis in the UK. Am R Coll Surg Engl 85:306-12.

19. Stephens M, Beaton C (2010) Early cholecystectomy after acute admission with cholecystitis: how much work?. World J Surg 34:2041-44.

20. Yamashita Y, Takada T, Hirata K (2006) A Survey of the timing and approach to the surgical Management of patients with acute colecystitis in Japanese hospitals. J Hepatobiliary Pancreatic Surg 13:409-15.

21. Mestral C, Laupacis A, Rotsein O et al (2013) Early cholecystectomy for acute cholecystitis: a population-based retrospective cohort study of variation in practices. CMAJ open 1(2):E62-7.

22. Askew J (2005) A survey of the current surgical treatment of gallstones in Queensland. ANZ J Surg 75:1086-9.

23. Barceló M, Cruz-Santamaría D, Alba-López C et al (2013) Advantages of early cholecystectomy in clinical practice of a tertiary care center. Hepatobiliary Pancreat Dis Int 12(1):87-93.

24. Germanos S, Gourgiotis S, MKocher H (2007) Clinical update: early surgery for acute cholecystitis. Lancet 369:1774-6.

25. De Mestral C, Rotsein O, Laupa A et al (2014) Comparative operative outcomes of early and delayed cholecystectomy for acute cholecystitis. Ann Surg 259(1): 10-7.

26. Greenwald JA, McMullen HF, Coppa GF et al (2000) Standardization of surgeoncontrolled variables. Impact on outcome in patients with acute cholecystitis. Ann Surg 231(3):339-44.

27. Hadad SM, Vaidya JS, Baker L et al (2007) Delay from symptom onset increases the conversion rate in laparoscopic cholecystectomy for acute cholecystitis. World $\mathrm{J}$ Surg 31:1298-1301.

28. The burden of gastrointestinal diseases. Bethesda, MD. American gastrointestinal Association, 2001.

29. Wilson E, Gurusamy K, Gluud C et al (2010) Cost-utility and value-of-information analysis of early versus delayed laparoscopic cholecystectomy for acute cholecystitis. Br J Surg 97:210-9.

30. Macafee DAL, Humes DJ, Bouliotis G (2009) Prospective randomized trial using cost-utility analysis of early versus delayed laparoscopic cholecystectomy for acute gallbladder disease. Br J Surg 96:1031-40. 
31. Johner A, Raymakers A, Wiserman SM (2013) Cost utility of early versus delayed laparoscopic cholecystectomy for acute cholecystitis. Surg Endosc 27:256-62.

32. Clasificación internacional de enfermedades $9^{\mathrm{a}}$ revisión modificación clínica. CIE·9·MC $8^{\text {a }}$ edición, enero 2012. (The International Classification of Diseases, 9th Revision, Clinical Modification. 1978, Commission on Professional and Hospital Activities, Ann Arbor, Michigan 48705). Editado por el Ministerio de Sanidad, Política Social e Igualdad, Secretaría General Técnica. (C) Ministerio de Sanidad, Política Social e Igualdad. Gobierno de España. ISBN: 978-84-7670-715-9. NIPO papel: 860-11-2647. Depósito legal: M-45671-2011.

33. Evolución y proyección de la esperanza de vida al nacer 1992-2011. Tablas de mortalidad de la población de España. Parámetros de evolución demográfica. Instituto Nacional de Estadística (INE). (National Institute of Statistics. Spain).

34. Yokoe M, Takada T, Strasberg SM et al (2013) TG13 diagnostic criteria and severity grading of acute cholecystitis. J Hepatobiliary Pancreat Sci 20:35-46.

35. Tsuyuguchi T, Itoi T, Takada T. et al (2013) TG13 indications and techniques for gallbladder drainage in acute cholecystitis. J Hepatobiliary Pancreat Sci 20:81-88.

36. Miura F, Takada T, Strasberg SM et al (2013) TG13 flowcharts for the management of acute cholangitis and cholecystitis. J Hepatobiliary Pancreat Sci 20:47-54.

37. Okamoto K, Takada T, Strasberg SM et al (2013) TG13 management bundles for acute cholangitis and cholecystitis. J Hepatobiliary Pancreat Sci 20:55-59.

38. Zakko S, Afdhal N. Vollmer C (2012) Treatment of acute cholecystitis. UpToDate, sep

39. Hatzidakis AA, Prassopoulos P, Petinarakis I et al (2002) Acute cholecystitis in high-risk patients: percutaneous cholecystostomy vs conservative treatment. Eur Radiol 12:1778-84.

40. Degrate L, Ciravegna AL, Luperto M et al (2013) Acute colecystitis: the Golden 72 hs period is not a strict limit to perform early cholecystectomy. Results from 316 consecutive patients. Langenbecks Arch Surg 398(8):1129-36.

41. Gurusumany KS, Rossi M., Davidson BR (2013) Percutaneous cholecystostomy for high-risk surgical patients with acute calculous cholecystitis. Cochrane Database Syst Rv Aug 12;8:CD007088.

42. Abi-Haidar Y, Sánchez V, Williams S et al (2012) Revisiting percutaneous cholecystostomy for acute cholecystitis based on a 10-year experience. Arch Surg 147(5):416-422.

43. Kortmam K, van Ramshorst B, Bollen T et al (2012) Acute cholecystitis in high risk surgical patients: percutaneous cholecystostomy versus laparoscopic cholecystostomy (CHOCOLATE trial): study protocol for a randomized controlled trial. Trials 13:7. 
44. Yamashita Y, Takada T, Kawarada Y et al (2007) Surgical treatmente of patients with acute colecistitis: Tokyo guidelines. J Hepatobiliary Pancreat Surg 14:91-97

45. Kiviluoto T., Siren J., Luukkonen P et al (1998) Randomized trial of laparoscopic versus open cholecystectomy for acute and gangrenous cholecystitis. Lancet 351:321-5. 


\section{Legend to figures}

Figure 1. Patients admitted $(n=967)$ with diagnosis of acute cholecystitis and treatment received during 2010, 2011 and 2012.

No surgery: patients with medical treatment. Urgent surgery: performed on the same day as admission. Early stage surgery: performed within the first four days of admittance. Late stage surgery: performed at a later time but during the same admission. Elective surgery: performed during another admission.

Figure 2: Treatment of patients admitted and their relationship with age. The green line represents the group of patients undergoing surgery, whereas the blue line refers to the medically treated patients. 